\title{
Construction Strategy of College English Flipped Classroom Teaching Model Based on MOOC
}

\author{
Yang Yade \\ School of Foreign Languages, Baoshan University, Baoshan City, Yunnan, China, 678000
}

Keywords: College English; Flipped Classroom; Teaching Mode; Construction

Abstract: With the continuous progress and development of science and technology, it has entered the era of electronic information, and the teaching mode of MOOC and "flipped class" has emerged as the times require. The flipped classroom teaching mode based on MOOC has greatly innovated the teaching mode of colleges and universities, and the disadvantages of traditional teaching methods have been well solved.

As a result of the rapid development of globalization and acclimatization, MOOC has become a focus of attention and research in education at home and abroad. MOOC platforms represented by ED X, Audacity and Concourse have also emerged one after another. As one of the main directions of the current college English teaching reform in China, the effective application of the flipped classroom teaching model is a necessary condition to improve the efficiency of College English teaching. At present, China's higher education reform has entered a critical period. How to combine the original teaching content with new technology, constantly innovate teaching methods and improve teaching efficiency is the central task facing college English classroom teaching. Therefore, only by combining MOOC with flipped classroom teaching mode and improving its shortcomings and shortcomings in classroom teaching can we achieve the overall improvement of College English classroom teaching level.

\section{MOOC}

MOOC is a term used in academic circles. It appeared in 2008. As a new way of learning, MOOC is rapidly becoming popular all over the world and attracted wide attention. Mocha has developed rapidly in the United States, Australia, the United Kingdom and other countries. Many other countries and regions in the world also show strong enthusiasm for Mocha and want to actively participate in it. Universities and academic institutions all over the world also show strong professional needs. The course consists of short videos, the shortest minutes and the longest ten minutes.

In the network age, Mu lesson is very consistent with the characteristics of fragmented reading: $\mathrm{Mu}$ lesson has many small questions, students have to answer the right questions to continue the lesson; $\mathrm{Mu}$ lesson assignments, deadlines for submitting homework, final exams, qualified examinations will be issued certificates; Mu lesson also has a course forum, if students encounter problems in learning, can also be in the forum. Posting for help, which is likely to receive the puzzles of the bullies from all over the world, works very well. In Mu class, English is the only 
language used, homework should be done in English, forum discussion should be done in English.

\section{The characteristics of college English flip classroom from the perspective of much course}

With the support of Internet technology, although mu-class and flip-class belong to different teaching modes in essence, they can be integrated accordingly. In this way, the teaching effect can be significantly improved and the teaching mode can be innovated. At the same time, they can better cultivate autonomous learning ability and make up for the limitations of traditional English classroom teaching. At present, the characteristics of flip classroom teaching based on Mu lesson are as follows, as shown in Table 1.

Table 1 The Characteristics of College English Flip Classroom from the Perspective of Much Course

\begin{tabular}{|c|}
\hline The Characteristics of College English Flip Classroom from the Perspective of \\
Much Course
\end{tabular}

\subsection{Resource sharing}

It has a close relationship with the internet. Mu class attaches great importance to the concept of resource sharing. It highly esteems the collection of relevant information, which can prepare lessons for teachers, provide rich resources, and also enable students to access resources provided by other schools. That is to say, based on the Internet, this kind of coursework can create an encyclopedia of learning resources for students.

\subsection{Can allocate learning time more scientifically}

In the traditional classroom, the teaching mode used is in-class teaching and in-class teaching. However, the classroom teaching time is relatively tight and the content is more. In terms of vocabulary, long and difficult sentences and text analysis, it needs to invest a lot of time. However, divergent thinking training and background knowledge analysis have been neglected to varying degrees. Turning over the classroom is to turn the traditional teaching order, to teach low-level knowledge and put it into the extracurricular, that is to say, to enable students to complete the self-study of knowledge independently, while the internalization of knowledge is placed in the classroom.

\subsection{Individualization of education}

Because there are significant differences among students, and teaching must adapt to these differences, which is also the core principle of current education. If classroom teaching is carried out according to the standardized and consistent model, it is easy to produce high-level students who have more ability to learn, and poor students are still difficult to keep up with the rhythm of learning. And flipping classroom teaching needs to give full play to nonadministrative in learning, so that students with different learning abilities can combine their own abilities, determine the corresponding classroom form, and control their learning time and learning difficulty accordingly. 


\subsection{Further promoting tenderheartedness of initiative}

In the environment of admiring lessons, students can log on the corresponding resource platform after class, and then study the content they are interested in, so that they are always in the key position of learning. In this way, students can not only decide what they learn independently, but also include the corresponding learning progress. In addition, they can also adjust their learning methods accordingly.

\section{Design of college English flip classroom teaching model based on MOOC}

From the perspective of curriculum design, the traditional classroom design mainly includes three steps, namely, the analysis of the front section, the design of activities and resources, and the design of teaching evaluation. The teaching mode of the flipped classroom described in this paper redesigns the time sequence and emphasis of the original classroom design, and improves the traditional way of knowledge imparting and knowledge internalization. Based on this, this paper designs the basic framework of MOO C-based College English Flip Classroom Teaching Model as follows, as shown in figure 1
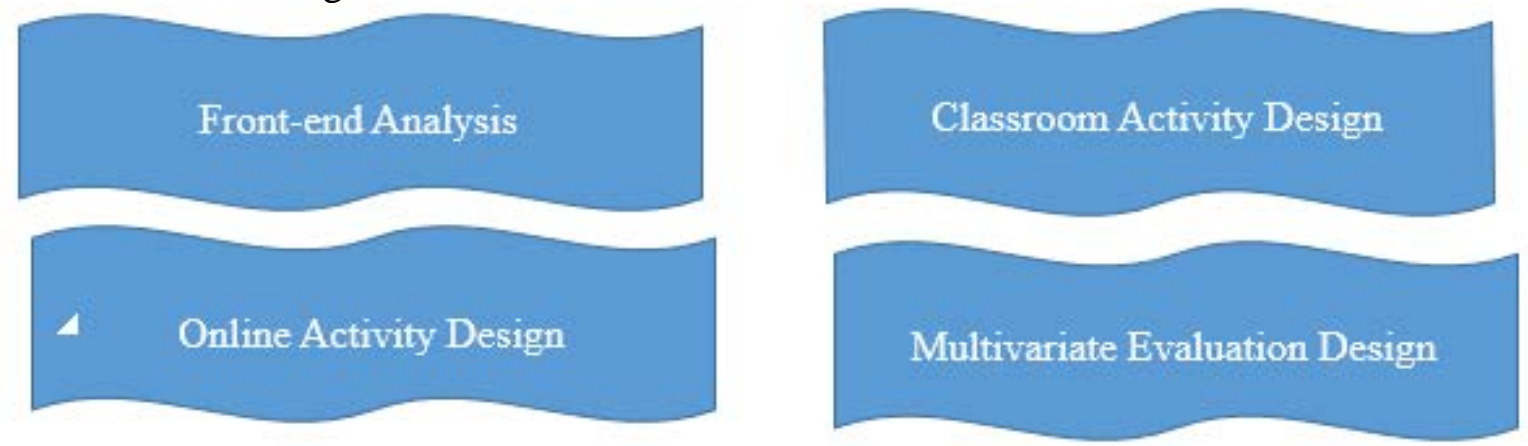

Figure 1 Design of College English Flip Classroom Teaching Model Based on MOOC

\subsection{Front-end analysis}

The front-end analysis of the curriculum mainly includes two parts, that is, the analysis of reteaching ideas and abilities, and the analysis of learners, learning content and other elements. After determining the class hours, the teachers can screen the corresponding courses through MOOC platform, analyze and understand the imparting of English language knowledge and learning methods, and formulate teaching objectives and teaching plans that are in line with the curriculum planning and studentship on the basis of combining the students' level and curriculum setting of the school.

\subsection{Online activity design}

Liechtensteiner activities mainly refer to the task of choosing and integrating teaching resources before students start learning, and dividing learning groups and formulating evaluation criteria according to the corresponding curriculum training objectives, on the basis of front-end analysis and combining teaching objectives and teaching plans. As far as college English is concerned, teachers should organize students to have group English conversations and discussions, and formulate evaluation criteria based on pronunciation, grammar and other factors. At the same time, when students encounter difficulties in the learning process, teachers are also responsible for guiding and answering questions. They can use micro-videos or text explanations to reasonably answer 
questionnaires in the light of the actual situation.

\subsection{Classroom activity design}

Flipping classroom activities under the classroom teaching mode is an important link to improve denuclearizing quality and prevent the loss of students in the classroom. It is also the essential difference between flipping classroom activities and online online courses. Therefore, when designing specific links, English teachers should pay attention to the value of face-to-face learning, avoid using the traditional classroom teaching mode of teacher-centered teaching, and set up scientific and reasonable teaching activities on the basis of understanding denuclearizing conditions, according to teaching objectives and the difficulties students need in online learning. For example, students are required to complete a project in the form of group oral report on the basis of independent learning, and give immediate feedback to the complementation level. Classroom activities are used as a basic platform to solve students' learning puzzles and improve their comprehensive quality.

\subsection{Multivariate evaluation design}

Due to the diversity of teaching methods and approaches in the MOOC mode of College English flip classroom teaching, we should also pay attention to the exchange and integration of various evaluation methods when evaluating the teaching effect. For example, through interactive dictation of vocabulary and on-line question-and-answer of classroom assignments, studentship learning level can be assessed, and formative assessment and nominative assessment can be flexibly used to give full play to the supervisory and guiding role of teaching evaluation.

\section{Conclusion}

We should see that the combination of MOOC and traditional classroom teaching mode is the inevitable requirement of the rapid development of scientific and technological information and the deepening reform of College English. However, the combination of MOOC and traditional classroom teaching is not equal to replacing traditional classroom teaching with MOOC, but to give full play to the advantages of all parties and introduce MOOC as a new teaching platform into college English flip classroom, so as to promote the communication and integration between teachers and students. To achieve the optimal development of teaching effect.

\section{References}

[1] An Menacing. Design of interactive teaching platform based on MOOC course [D]. South China University of Technology, 2015.

[2] He Went. Research on Flipping Classroom and Its Teaching Practice [D]. Hen an Normal University, 2014.

[3] Deng Ding. Research on the Reversal Classroom Teaching Model Based on MOOC [J]. China Audiovisual Education, 2015 (4).

[4] Bhang Mullein. Research on the Reversal Classroom Teaching Model Based on Mu Course: Taking the Follow-up Course of College English as an Example [J]. Modern Educational Technology, 25 (8).

[5] Bin Xiaoping. Research on the College English Flip Classroom Teaching Model Based on Mu-curricular Resources [J]. Journal of Jilin Institute of Education, 2016,32(2): 74-76. 